\title{
COVID-19: timely action to prevent local transmission: a success story from Kannur District, Kerala
}

\author{
Anitha Subhadra Saraswathy ${ }^{1}$, Ameena Subair Raheela ${ }^{2 *}$, Rameela Sanya ${ }^{3}$, \\ Veena Vandichalil Morakkan ${ }^{4}$, Bejoy Chalil Paleri ${ }^{2}$, Murali Koppentavida ${ }^{2}$, Steena Kuriakose ${ }^{5}$, \\ Deepak Rajan ${ }^{6}$, Shaj Mullankandy Konoth ${ }^{7}$, Preetha Muduvana, \\ Jayasree Anandabhavan Kumaran', Narayana Naik ${ }^{10}$, Sanoj Akkanissery Koomullil ${ }^{11}$, \\ Nithin Radhakrishnan ${ }^{12}$, Rahul Kizhakkemadathil Rajagopalan ${ }^{13}$
}

\author{
${ }^{1}$ Assistant Professor, Department of Community Medicine, Government Medical College, Kannur, Kerala, India \\ ${ }^{2}$ Assistant Surgeon, Department of Health Services, Kannur, Kerala, India \\ ${ }^{3}$ Junior Resident, Department of Community Medicine, Government Medical College, Kannur, Kerala, India \\ ${ }^{4}$ Civil Surgeon, Department of Health Services, Kannur, Kerala, India \\ ${ }^{5}$ Epidemiologist Intern, National Health Mission, Kannur, Kerala, India \\ ${ }^{6}$ District Epidemiologist, ${ }^{7}$ District Surveillance Officer, ${ }^{8}$ Deputy District Medical Officer, ${ }^{10}$ District Medical Officer, \\ District Medical Office, Kannur, Kerala, India \\ ${ }^{9}$ Professor and Head, Department of Community Medicine, Government Medical College, Kannur, Kerala, India \\ ${ }^{11}$ Senior District Co-ordinator, Palliative Care, National Health Mission, Kannur, Kerala, India \\ ${ }^{12}$ Public Relation Officer, National Health Mission, Kannur, Kerala, India \\ ${ }^{13}$ District Accredited Social Health Activist Coordinator, National Health Mission Kannur, Kerala, India
}

Received: 09 February 2021

Revised: 08 March 2021

Accepted: 09 March 2021

\section{*Correspondence:}

Dr. Ameena Subair Raheela,

E-mail: ameenasr12@gmail.com

Copyright: (c) the author(s), publisher and licensee Medip Academy. This is an open-access article distributed under the terms of the Creative Commons Attribution Non-Commercial License, which permits unrestricted non-commercial use, distribution, and reproduction in any medium, provided the original work is properly cited.

\begin{abstract}
Background: The first case of COVID-19 in Kannur district was reported in first week of March, 2020. An elderly female with multiple co-morbidities and confined to house for many years was detected to be positive for SARSCoV-2 on third week of May, 2020. She neither had relevant travel history nor was a contact of any confirmed COVID-19 case. A special investigation team was assigned to identify the source of infection.

Methods: Index case's residential premises and the concerned local Primary Health Centre (PHC) were visited to get an idea about the background details of the index case. The team members participated in focus group discussions for decision making and reviewing steps involved in the process of investigation. Data collection was done mainly through phone interviews using an open- ended questionnaire. Data collected from family members, relatives, neighbours and local leaders were compiled systematically and summarized descriptively to reach a hypothesis.

Results: Rigorous contact tracing of index case and appropriate testing of the contacts were done. Interstate truck drivers bringing fish from outside Kerala, who used to deliver fish to the index case's house were identified as the source of infection. These truck drivers used to deliver fish in the local fish market also. The district administration was immediately alerted and fish market was disinfected and closed which prevented further mushrooming of cases. Conclusions: Early epidemiological investigation for source identification and elucidation of chain of disease transmission is crucial to clamp down the outbreak efficiently.
\end{abstract}

Keywords: COVID-19, Epidemiological investigation, Kannur, Kerala 


\section{INTRODUCTION}

The initial case of Corona Virus Disease-19 (COVID-19) in Kannur district was reported in the first week of March, 2020. ${ }^{1}$ In the initial phase, the disease was found only among those with recent international or interstate travel history and among their close contacts. An elderly female with multiple co-morbidities and confined to house for many years turned positive for Severe Acute Respiratory Syndrome-Corona-Virus-2 (SARS-CoV-2) on third week of May, 2020. She neither had any recent travel history nor was a contact of any confirmed COVID-19 case. As per the direction of District Medical Officer Kannur, it was decided to conduct an epidemiological investigation for identifying the source of infection. A special investigation team was formed with representatives from Health Service Department and Department of Community Medicine, Government Medical College Kannur for this purpose. The aim of the investigation was to identify the possible source of infection of the index case.

\section{METHODS}

A descriptive study for outbreak investigation was conducted in a rural Primary Health Centre (PHC) in Kannur district. The study period was from May 2020 to June 2020. The area was visited to assess the background details and focused group discussions were conducted to figure out the probable sources of infection. It was found that the index case had multiple co-morbidities for last 18 years and was confined to her house. She had a few hospital visits in the recent past and was admitted in two hospitals; initially in the third week of April and then on second week of May and was later detected to be COVID-19 positive while she was admitted in the third hospital on 18.5.2020.

Patient's residential premises were also visited to get a first-hand knowledge about the environmental characteristics. Data collection was done mainly through phone interviews using an open- ended questionnaire. Data were summarized descriptively and systematically to reach a hypothesis.

The present epidemiological investigation which began on third week of May 2020, submitted the final report on second week of June, 2020.

\section{Ethical considerations}

The present study is the report of an epidemiological investigation done as instructed by District Medical Officer, Kannur. Hence it was exempted from obtaining clearance from Institutional Ethics Committee.

However, informed verbal consent was taken from the participants. Confidentiality and privacy were maintained at every step of the investigation.

\section{Epidemiological investigation steps}

Preparation of plan of action: An action plan was formulated from the preliminary information obtained regarding the index case well before the commencement of actual field investigation.

\section{Plan included}

- Detailed history taking and tracing of all possible contacts of index case.

- Testing of family members with high social exposure, who might have transmitted infection to index case.

- Testing of primary contacts at hospital (Index case had admitted in two different hospitals from 20.4.2020 to 27.4.2020 and 10.5.2020 to 17.5.2020. And on 18.5.2020 swab testing was done from another hospital).

- To execute quarantine and testing of contacts as per State guidelines.

The action plan prepared for epidemiological investigation is depicted in (Table 1).

\section{Visit to the primary health centre}

It helped to build rapport between the team members. The background details of the index case were ascertained. Focused group discussions conducted in the PHC aided in taking decision making steps, figuring out probable sources of infection and reviewing of the investigation steps.

\section{Visit to the residential premises of the index case}

It was done to get a first- hand knowledge of the environmental characteristics. Some ecological factors like road accessibility, neighbourhood type were also looked into. Evidence of direct fish delivery to the backyard of index case's house was observed by finding out many fish boxes stocked in the premises of house.

\section{Descriptive epidemiology}

Data collected from family members, relatives, neighbours, local leaders etc were recorded, compiled and systematically summarized. The history of index case from 14 days before symptom onset until isolated was mapped and close contacts were identified. Tracing of contacts of index case in 14 days period prior to symptom onset was done to identify the source of exposure, and it also allowed for further active case-finding around the source. Contact tracing after symptom onset until isolation was done to identify exposed individuals to initiate quarantine measures to break the transmission chain. All high risk primary contacts and all symptomatic contacts were tested whereas all the remaining contacts were quarantined. Activity maps of all the positive cases obtained were critically examined and crosschecked to 
establish potential exposures and to identify epidemiological links between cases within the cluster.

\section{Flow chart preparation}

Flowchart was chronologically sequenced and aligned with epidemiological links and it helped to understand the evolution of whole cluster of cases from the source. The depiction easily allowed the team members to find out the control measures needed to take further steps to break the transmission chain.

\section{Implementation of control activities}

The source of infection which had the potential to result in numerous clusters of COVID-19 cases was identified, closed and disinfected.

\section{Surveillance}

Sentinel surveillance was carried out in the area to find out any unidentified cases.

\section{Table 1: Action plan prepared for investigation.}

\begin{tabular}{|c|c|c|}
\hline Actions to be taken & Target group & Purpose \\
\hline \multirow{4}{*}{ Swab test (RT-PCR) } & a. Index case & Confirmation of diagnosis \\
\hline & $\begin{array}{l}\text { b. Care takers and family members who had } \\
\text { close contact with index case since } 1.5 .2020\end{array}$ & Testing of primary contacts \\
\hline & $\begin{array}{l}\text { c. }{ }^{*} \text { Staff of hospital where the case was } \\
\text { admitted at the time of diagnosis (doctors, staff } \\
\text { nurse, attender, cleaning staff etc) in ICU/ward } \\
\text { who had close contact with index case from } \\
\text { 10.5.2020 to 17.5.2020 }\end{array}$ & Testing of primary contacts \\
\hline & $\begin{array}{l}\text { d. Patients who were in ICU along with index } \\
\text { case between 10.5.2020 and 17.5.2020 }\end{array}$ & To rule out cross-infection \\
\hline \multirow{4}{*}{$\begin{array}{l}\text { Contact tracing of index } \\
\text { case }\end{array}$} & $\begin{array}{l}\text { a. Care takers and family members in the house } \\
\text { of index case since } 1.5 .2020\end{array}$ & \multirow{4}{*}{$\begin{array}{l}\text { To identify possible source of } \\
\text { infection }\end{array}$} \\
\hline & $\begin{array}{l}\text { b. Staff of hospital where the case was admitted } \\
\text { at the time of diagnosis (doctors, staff nurse, } \\
\text { attender, cleaning staff etc) in ICU/ward from } \\
\text { 10.5.2020 to } 17.5 .2020\end{array}$ & \\
\hline & $\begin{array}{l}\text { c. Patients who were in ICU/ward along with } \\
\text { index case between } 10.5 .2020 \text { and 17.5.2020 }\end{array}$ & \\
\hline & d. Visitors at hospital/house since 1.5 .2020 & \\
\hline \multirow{4}{*}{ Detailed history taking } & a. Primary contacts within the family & $\begin{array}{l}\text { To identify high risk job and travel } \\
\text { within and outside district }\end{array}$ \\
\hline & b. Visitors at hospital/house since 1.5 .2020 & $\begin{array}{l}\text { To identify high risk job/ travel } \\
\text { history/contact history with persons } \\
\text { having travel history/COVID suspect/ } \\
\text { COVID positive case }\end{array}$ \\
\hline & $\begin{array}{l}\text { c. *Primary contacts of index case during } \\
\text { hospital stay from } 20.4 .2020 \text { to } 27.4 .2020\end{array}$ & $\begin{array}{l}\text { To rule out remote possible chance of } \\
\text { infection }\end{array}$ \\
\hline & $\begin{array}{l}\text { d. Hospital and house visitors of index case } \\
\text { from } 20.4 .2020 \text { to } 27.4 .2020 \text { and } 20.4 .2020 \text { to } \\
30.4 .2020 \text { respectively. }\end{array}$ & $\begin{array}{l}\text { Identification of high risk close } \\
\text { contacts in the immediate past }\end{array}$ \\
\hline
\end{tabular}

*Those with travel history/contact history with persons having travel history/COVID suspect/ COVID positive to be given priority for testing
One such case identified was also epidemiologically linked to the cluster under study and early identification helped to arrest further transmission.

\section{Findings communicated}

The interim reports and final report of the investigation were communicated to the District Surveillance Unit (DSU), Kannur.

\section{RESULTS}

\section{Background}

It was found that the index case had multiple comorbidities for last 18 years and was confined to her house. She had three episodes of hospital admissions, viz. in the 3rd week of April, 2nd and 3rd week of May. In the last episode of admission patient had vomiting, fever and breathlessness and the swab tested for SARS-CoV-2 was positive. 
Index case was survived by husband, children and grandchildren. She was taken care of by the family members and visited by close relatives on and off at home. Of the total 37 family members, 26 were living in the same household of the index case.

Table 2: Age distribution of COVID-19 positive individuals within the family.

\begin{tabular}{|llll|}
\hline $\begin{array}{l}\text { Age } \\
\text { group } \\
\text { (years) }\end{array}$ & $\begin{array}{l}\text { Total no. of } \\
\text { individuals }\end{array}$ & $\begin{array}{l}\text { No of } \\
\text { individuals } \\
\text { positive for } \\
\text { COVID-19 }\end{array}$ & Percentage \\
\hline Up to $\mathbf{1 0}$ & 10 & 3 & 30 \\
\hline $\mathbf{1 1 - 2 0}$ & 11 & 3 & 27.27 \\
\hline $\mathbf{2 1 - 4 0}$ & 7 & 3 & 42.85 \\
\hline $\mathbf{4 1 - 6 0}$ & 7 & 2 & 28.57 \\
\hline $\mathbf{6 1 - 8 0}$ & 2 & 2 & 100 \\
\hline
\end{tabular}

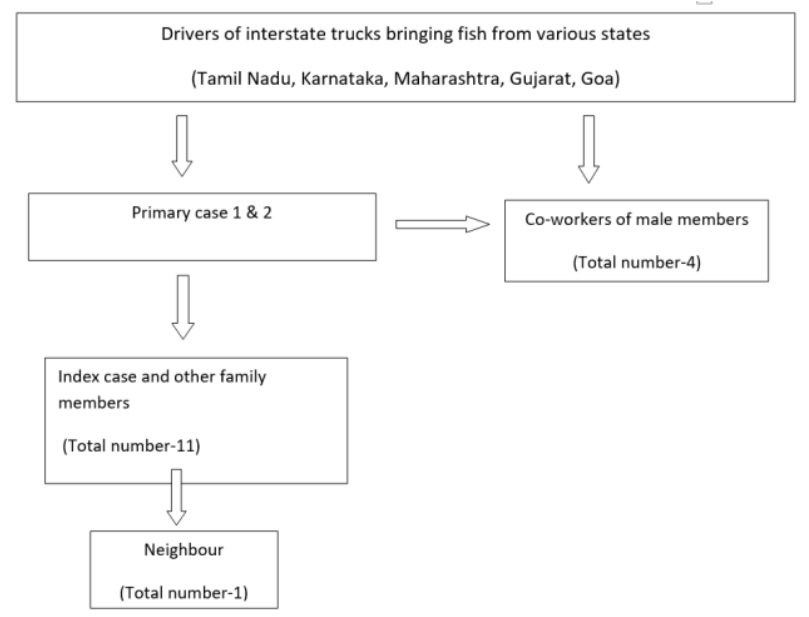

Figure 1: Probable chain of disease transmission.

\section{Contact tracing}

Primary contacts of the index case belonged to two categories only. One category was the hospital staff and patients in the hospitals where index case had visited and admitted. Second category was the family members. All high risk primary contacts and symptomatic contacts of the index case were tested for SARS-CoV-2. None of the hospital contacts were positive on testing. Hence the focus of source was shifted to family circle. Majority of male members in the family were fish dealers and had contact with fish distributors. Female members were not employed and had interactions with females of neighbourhood.

The family members were tested and it was found that 12 members of the family, other than the index case were positive for SARS-CoV-2. Out of the twelve positives, 9 were either female members or children. This could narrow down the point towards the other three male members. Out of them one was elderly and spouse of the index case who was confined to family due to nationwide lockdown. The other two male members were active in fish trade since lockdown did not impose any restrictions to markets. It was assumed that these two were the primary cases of the cluster.

\section{Epidemiological link}

Primary cases had frequent contact with interstate truck drivers as part of the business. These interstate truck drivers were bringing fish from different states like Gujarat, Karnataka, Tamil Nadu, Goa and Maharashtra. These states were reporting large number of COVID-19 cases during that time. These interstate truck drivers were identified as the source of infection to the male members in the family, who in turn transmitted infection to the index case and other family members.

Interstate truck drivers used to deliver fish to the premises of index case's house. There were rumours that after delivering fish boxes to the backyard of the house, interstate truck drivers/cleaners used to stay back in the dilapidated building next to index case's house for refreshment and rest, but this could not be established. If so, this might have been an additional exposure to the family members of primary cases compared to other coworkers who got infection but whose family members were exempted from being infected.

Overcrowding in the house of primary cases also might have a role in spread of infection within the family. Hence repeated exposures from both the primary cases and the sources thus contributed to increased number of cases among the family members. The same truck drivers also supplied fish to the wholesale fish markets in Kannur district. Considering the risk of exposure to fish merchants, dealers and customers visiting the fish markets, District administration was alerted. The fish market frequented by the male members of index case family and interstate truck drivers was disinfected and closed.

\section{Surveillance}

Influenza-like illness (ILI) surveillance was done in neighbourhood area and among workers in the fish market. One of the neighbour who used to visit the house of index case was also tested positive. Four co-workers of the primary cases working in the fish market were also detected to have SARS-CoV-2.

\section{Testing summary}

A total of 252 primary contacts and 511 secondary contacts were traced. Sentinel surveillance was also done in the field area and fish market area to pick any cases 
which might have been missed. A total of 18 individuals were tested positive for SARS-CoV-2 including index case, out of 283 in the cluster with a test positivity rate of $6.3 \%$.

\section{Clinical profile}

Out of 18 positive individuals, only 3 persons (16\%) were symptomatic. Symptoms reported were fever, sore throat and rhinitis. Only one individual (index case) succumbed to death, making case fatality rate $5.5 \%$. Among three family members who had one or other co-morbidities, two persons developed COVID-19 infection. Basic reproduction number for infection within the family was found to be 5.5 , as 11 family members were infected by two primary cases. Out of the total 24 susceptible members in the house two developed symptoms resulting in Secondary attack rate (SAR) of $8.3 \%$. Age distribution of COVID-19 positive individuals within the family is shown in (Table 2).

\section{DISCUSSION}

Closure of high risk area favouring disease transmission should be done early to check the spread of outbreak. In China, where the outbreak started initially, it was found that banning public gatherings, public transport within the cities and closure of entertainment venues were associated with reduction in case incidence. It was also observed that cities in China that implemented control measures early, reported fewer average numbers of cases (13.0) in the first week of their outbreaks compared with cities that initiated control measures later (20.6). ${ }^{2}$

Contact tracing is needed to identify the possible source of infection and also to quarantine high risk contacts to arrest further spread. The active surveillance of close contacts of confirmed COVID-19 cases and the implementation of control measures, including home quarantine for those exposed, decreases the risk of human-to-human transmission originating from imported cases and subsequently delay propagation of the virus in the general population. ${ }^{3}$

The containment strategy put forward by Government of India also emphasized on early detection, breaking the chain of transmission in the defined geographic area by quarantine, isolation, social distancing, and active surveillance and testing all suspected cases. As the route of transmission among humans was already narrowed down to respiratory secretions, close contact and indirect transmission through contaminated surfaces, appropriate preventive measures like use of face mask, hand washing and social distancing could be implemented. ${ }^{4}$

Meticulous contact tracing and quarantine measures are the mainstay in prevention of COVID-19 outbreaks. A detailed study of the primary contacts is essential for two reasons to identify individuals with high social exposure who might have been the primary case and immediate quarantine of those with high social exposure to prevent further transmission and occurrence of an outbreak.

While first case of novel corona virus disease 2019 in India was reported in Kerala in January 2020, the first case in Kannur district in Kerala occurred two months later in March 2020. Till May 2020, the COVID-19 cases in Kannur were only among international travellers and interstate travellers or their primary contacts. This was so due to the 28 days strict quarantine measures followed for interstate and international travellers and also the awareness generated among the community regarding the preventive measures, and motivating them to follow the same.

The identification in May 2020 of a COVID-19 case in an individual with no travel or COVID-19 contact history alerted the District Health Department to a change in transmission pattern in the district. Considering the urgency of the situation and necessity of identification of source to prevent further outbreaks, source identification strategy was geared up with a team approach. District Corona Surveillance Committee with representatives from Health Service Department and Regional Prevention of Epidemic and Infectious Disease Cell (RPEID cell) Department of Community Medicine, Government Medical College Kannur was constituted in April 2020 itself for surveillance and timely intervention. When a COVID-19 case with unknown source was identified, a special team was designated to identify the source of that case and to initiate control measures.

In the present investigation Influenza-like illness (ILI) surveillance was done in the locality of index case residence and among workers in the fish market. Sentinel surveillance was also done in the field area and fish market area to pick any cases which might have been missed. A total of 18 individuals were positive for SARSCoV-2 out of 283 individuals tested and among those positive, 13 individuals including the index case belonged to the same household. In a study done by Qin-Long Jing et al, to study secondary attack rate (SAR) among household contacts and its determinants, it was found that SARS-CoV-2 was more transmissible in households than SARS-CoV-1 and MERS-CoV and elderly were the most vulnerable for household transmission. ${ }^{5}$

Epidemiology and Case Management Team, Korea Centres for Disease Control and Prevention investigated 2370 contacts of first 30 cases in Republic of Korea between 2020 January 24 and 2020 March 10 and found that SAR was $7.56 \%$ among household contacts compared to $0.55 \%$ among all contacts. The study found that transmission of COVID-19 was significant among household contacts. ${ }^{6}$ It is comparable to SAR of $8.3 \%$ obtained in our setting.

A total of 18 individuals were tested positive for SARSCoV-2 out of 283 in the cluster with a test positivity rate of $6.3 \%$. The most common symptoms of COVID-19 are 
fever, dry cough, breathing difficulty and tiredness, and a few patients also present with nasal congestion, sore throat, diarrhea or aches and pains. ${ }^{7}$ Elderly individuals and persons with multiple comorbidities have high risk of mortality due to COVID- $19 .{ }^{8}$ In the present cluster, out of 18 positive individuals, only 3 persons (16\%) were symptomatic. Symptoms reported were fever, sore throat and rhinitis. Only one individual (index case) succumbed to death, making case fatality rate $5.5 \%$. Among three family members who had one or other co-morbidities, two persons developed COVID-19 infection.

Basic reproduction number (R0) for infection within the family was found to be 5.5, as 11 family members were infected by two primary cases. A higher value obtained may be due to the formation of family cluster. In a metanalysis of published articles on COVID-19 basic reproduction number, the mean of reported $\mathrm{R} 0$ was $3.38 \pm 1.4$ and pooled R0 was estimated to be $3.32(95 \%$ confidence interval, 2.81 to 3.82$){ }^{9}$ A systematic review found that the estimated mean R0 for COVID-19 is around 3.28, with a median of 2.79 and IQR of 1.16, and it was considerably higher than the WHO estimate of 1.95. These estimates of R0 may vary depend on the estimation method used as well as the validity of the underlying assumptions. R0 for COVID-19 is expected to be around $2-3$, which is broadly consistent with the WHO estimate. ${ }^{10}$

The early initiation of quarantine and isolation measures and closure of fish market for disinfection and testing of workers in the market prevented the occurrence of an outbreak in that area. Out of the 18 positive individuals, 13 were family members staying in the same household, one was their neighbour who used to visit their house and rest were either friends or co-workers in the market of COVID-19 positive male members in the family. The onset of these cases could not be prevented as transmission might have occurred before or at the same time as origin of index case. But the interventions prevented the occurrence of further transmission of infection within the market and occurrence of large outbreaks.

The experience from Kannur shows the importance of timely intervention to prevent outbreaks. In areas with only few cases of COVID-19, each case with unidentified source must be studied in detail so that the source can be identified and control measures initiated.

\section{Limitations}

Even though truck drivers from Gujarat, Maharashtra, Goa, Tamil Nadu and Karnataka used to deliver fish to the market, only drivers from Tamil Nadu and Karnataka could be traced and contacted over phone. None of the drivers could be tested using RT-PCR/Antibody test to establish infection among them.

\section{CONCLUSION}

The experience from Kannur shows the importance of timely intervention to prevent outbreaks. In areas which are experiencing early phase of pandemic or where fewer cases of COVID-19 get reported, each case with unidentified source must be studied in detail in order to identify the source of infection so that appropriate preventive measures can be implemented.

\section{ACKNOWLEDGEMENTS}

Authors would like to thank field staff of Department of Health Services Kannur, District corona surveillance committee Kannur, Integrated Disease Surveillance Programme Kannur, Corona control cell Kannur, Department of Community Medicine Government Medical College Kannur, Cyber Cell Kannur, District Health Authorities, National Health Mission, District Police Force and District Administration Kannur for their constant support.

Funding: No funding sources

Conflict of interest: None declared

Ethical approval: Not required

\section{REFERENCES}

1. Daily - Bulletin - HFWD - English - June - 12. pdf Available at https:// dhs. kerala. gov.in/wp-content/ uploads/ 2020 /06/Daily-Bulletin-HFWD-EnglishJune-12.pdf. Available at 21 August 2020.

2. Tian H, Liu Y, Li Y, Wu CH, Chen B, Kraemer MUG, et al. An investigation of transmission control measures during the first 50 days of the COVID-19 epidemic in China. Science. 2020;368(6491):638-42.

3. Euro Surveillance. Available at https:// www. eurosurveillance.org/ docserver/ fulltext/ eurosurveillance/ 25/ 6/ eurosurv-2 5 -6-4.pdf? expires $=1604843633 \&$ id=id \&accname $=$ guest $\&$ chec ksum=E1CF112AC2CC7E1E2ED7CE19522A49B. Accessed on 20 November 2020.

4. Containmentplan16052020.pdf. Available at https:// www.mohfw.gov.in/pdf/Containmentplan16052020. pdf. Accessed on 8 November 2020.

5. 2020.04.11.20056010v1.full.pdf. Available from: https://www.medrxiv.org/content/10.1101/2020.04.1 1.20056010v1.full.pdf. Accessed on 8 November 2020.

6. Coronavirus Disease-19: Summary of 2,370 Contact Investigations of the First 30 Cases in the Republic of Korea. Osong Public Health Res Perspect. 2020;11(2):81-4.

7. Coronavirus disease (COVID-19). Available at https:// www. who. int/ news- room/q -a-detail/ coronavirus -disease-covid-19. Accessed on 8 November 2020.

8. Clinical Management. Available at clinicalmanagement-of-novel-cov.pdf. https:// www. 
who.int/docs/default-source/coronaviruse/clinicalmanagement-of-novel-cov.pdf. Accessed on 2 January 2021.

9. Jpmph-20-076. Available at https:// www. jpmph.org/upload/pdf/jpmph-20-076.pdf. Accessed on 8 January 2021.

10. Liu Y, Gayle AA, Smith A, Rocklöv J. The reproductive number of COVID-19 is higher compared to SARS coronavirus. J Travel Med.

Cite this article as: Saraswathy AS, Raheela AS, Sanya R, Morakkan VV, Paleri BC, Koppentavida M, et al. COVID-19: timely action to prevent local transmission: a success story from Kannur District, Kerala. Int J Community Med Public Health 2020;27(2):46-54. 